\section{Incredible strength and easy application}

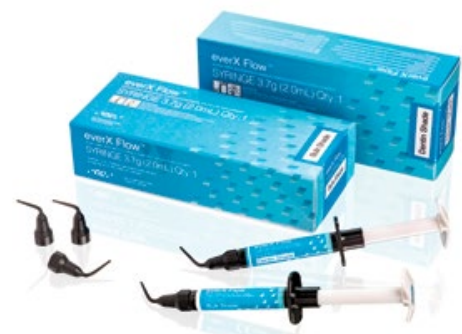

With its incredible strength and easy application, in two shades - everX Flow is set to be your new go-to product for all your restorations in need of a strong core.

everX Flow is a

short-fibre, reinforced flowable composite designed to replace dentine and reinforce even the largest restorations while simultaneously preventing them from cracking.

Offering high wear resistance and superb aesthetics, what makes everX Flow stand apart is its excellent fracture toughness, close to that of dentine, due to the high amount of short fibres strongly bonded to the resin matrix. Its thixotropic viscosity allows it to adapt perfectly to the cavity floor without slumping, even when placed in upper molars.

everX Flow's Bulk shade offers a depth cure of $5.5 \mathrm{~mm}$, ideal for deep posterior cavities, while the Dentin shade has a depth cure of $2 \mathrm{~mm}$ for highly aesthetic results and core build-up.

To find out more contact GC UK Ltd on 01908 218999, email Info.uk@gc.dental or visit www.gceurope.com.

\section{A complete decontamination solution}

Ensure best practice in decontamination with a powerful solution that boasts $99.999 \%$ efficacy against harmful diseases.

Continu products manufactured by Nuview have been independently tested to effectively protect against harmful diseases, including Hepatitis A, Hepatitis B, HIV, MRSA, salmonella and tuberculosis. This is a result of Continu's alcohol-free, waterbased formula, which has been developed to help practices achieve high levels of compliance in accordance with HTM 01-05 requirements.

Gentle on skin, the Continu range includes products for the cleaning and disinfection of hands, various surfaces, dental instruments and equipment - offering a complete solution to complement your infection control protocols. Contact Nuview for further details.

For more information call Nuview on 01453 872266, email info@nuview-ltd.com, visit www.nuview.co or 'like’ Nuview on Facebook.

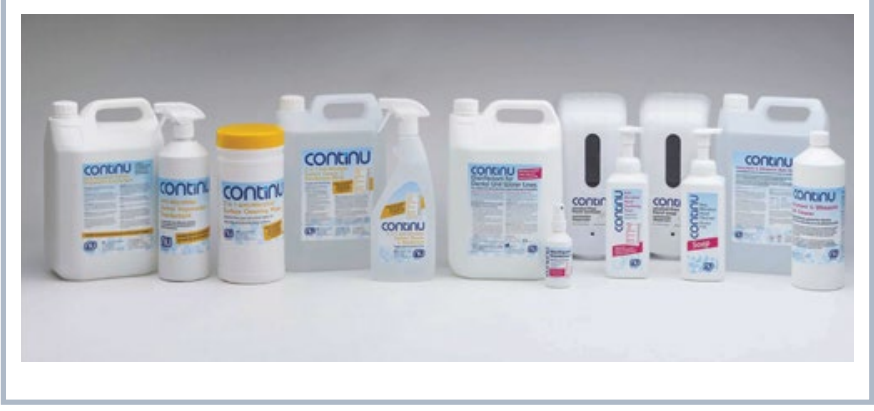

\section{Dental implantology: save the date}

The Association of Dental Implantology (ADI) remains as committed as ever to supporting education in the field of dental implantology.

As part of the many educational and networking benefits available to ADI members, the Members' National Forum is a particularly popular occasion for members across the country. It offers ADI members the opportunity to get up-to-date with the very latest ideas, materials and concept in dental implantology, while also meeting with like-minded peers.

To hear from ADI members including industry-leading speakers and stay abreast of the cutting-edge innovations in implant dentistry today, save the date for the ADI Members' National Forum 2019!

ADI Members' National Forum 2019 - Saturday 23 November Royal College of Physicians, London

This event is exclusive to ADI members and is FREE to attend. For more information or to join the ADI, please visit www.adi. org.uk.

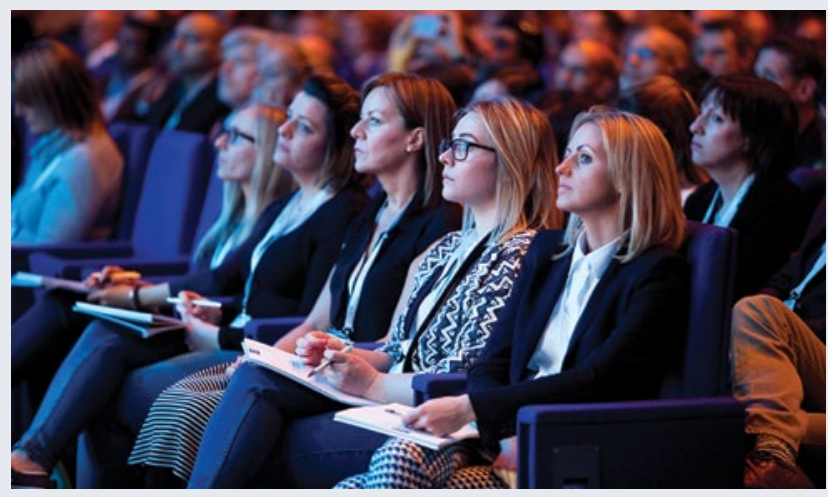

\section{Dedicated to relieving pain, not causing it}

Do you have patients who are scared of root canal treatment because they think it's going to hurt? Are you finding it difficult to provide the care that these individuals need because of this fear?

EndoCare is dedicated to relieving pain, not causing it. All of its team members have extensive specialist experience in supplying pain-free endodontic treatments and can help put your patients' minds at rest before giving them the treatment they require.

As part of EndoCare's philosophy it understands that every patient should be able to enjoy a comfortable, pain-free experience.

EndoCare has two practices in the London area, one in Richmond and the other in Harley Street, and are happy to help deliver the treatment your patients need before they head back to you for their routine care. Dental pain can cause patients a lot of problems, but with the help of EndoCare, fear of treatment doesn't have to be one of them.

For further information call EndoCare on 0207224 0999 or visit www.endocare. co.uk.

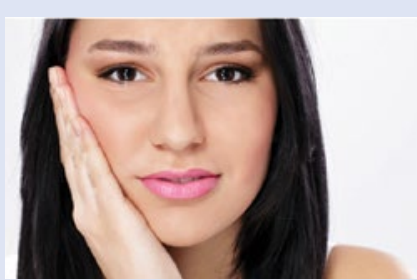

